\title{
Perturbation dynamics of a planktonic ecosystem
}

\author{
Katherine Healey ${ }^{1}$ \\ katiehealey@shaw.ca \\ Adam H. Monahan ${ }^{1}$ \\ monahana@uvic.ca \\ Debby Ianson ${ }^{2}$ \\ debby.ianson@pac.dfo-mpo.gc.ca
}

${ }^{1}$ School of Earth and Ocean Sciences, University of Victoria, PO Box 3055 STN CSC, Victoria, British Columbia, V8W 3P6, Canada

${ }^{2}$ Fisheries and Oceans Canada, Institute of Ocean Sciences, PO Box 6000, Sidney, British Columbia, V8L 4B2, Canada

Submitted to Journal of Marine Research as an article August 20, 2008 


\begin{abstract}
Planktonic ecosystems provide a key mechanism for the transfer of $\mathrm{CO}_{2}$ from the atmosphere to the deep ocean via the so-called "biological pump". Mathematical models of these ecosystems have been used to predict $\mathrm{CO}_{2}$ uptake in surface waters, and more recently have been embedded in global climate models. While the equilibrium properties of these models are well studied, less attention has been paid to their response to external perturbations, despite the fact that, as a result of the variability of environmental forcing, such ecosystems are rarely, if ever, in equilibrium. Human induced perturbations to these ecosystems, namely the addition of limiting nutrients (e.g. iron) to areas where nitrate is plentiful to accelerate the biological pump, have been proposed as a solution to reduce atmospheric $\mathrm{CO}_{2}$. In this study, linear theory is used to determine the structure of initially "unit-norm" perturbations to state variables of a five state variable ecosystem model in steady state, describing Ocean Station $\mathrm{P}\left(50^{\circ} \mathrm{N} 145^{\circ} \mathrm{W}\right)$ in summer, that optimize either instantaneous export flux of organic matter at fixed times or integrated export as the ecosystem relaxes towards equilibrium. A common feature in the optimization experiments for both instantaneous and integrated flux is the synchronization of the oscillatory behavior between two state variables. Because of these oscillations, there is an indirect contribution to the export flux that is non-intuitive. For all perturbations, it is found that the flux to higher trophic levels is the primary contributor to export flux, and, contrary to expectations, the contribution of aggregation is negligible.
\end{abstract}




\section{Introduction}

Atmospheric carbon dioxide $\left(\mathrm{CO}_{2}\right)$ dissolves in the surface waters of the oceans, and phytoplankton fix some of this $\mathrm{CO}_{2}$ through photosynthesis, transforming it into particulate organic carbon (POC). A portion of this POC, denoted exported carbon, eventually reaches the deep ocean, where it remains essentially out of contact with the atmosphere on climate time scales (i.e. 1000 years). This process is known as the "biological pump", and enhances the ocean's ability to store carbon (Sarmiento and Gruber, 2006, Volk and Hoffert, 1985). Although phytoplankton growth is often limited by light or nutrients, it is not, in general, limited by carbon, and an increase in atmospheric $\mathrm{CO}_{2}$ will not directly accelerate the biological pump.

There are large areas of the ocean where major nutrients (e.g. nitrogen), the lack of which is limiting to photosynthesis, are available and not drawn down to limiting concentrations by primary production. These are called high nutrient low chlorophyll (HNLC) regions, and include the subarctic North Pacific and Southern Ocean (de Baar et al., 2005). Martin et al. (1989, 1991) hypothesized that phytoplankton growth in HNLC regions is limited by the micronutrient iron, and it has been suggested that atmospheric $\mathrm{CO}_{2}$ may be reduced by fertilizing HNLC areas with iron to enhance the biological pump. An increase in phytoplankton biomass has been observed following both natural (e.g. Jo et al., 2007) and synthetic (e.g. Saito et al., 2006) iron fertilization events, however exported carbon in response to these events may only be measured indirectly (e.g. Wong et al., 2006). In general, blooms such as these have not been occupied long enough to observe responses in export; thus the effect of iron fertilization on export dynamics remains uncertain. 
Because of the importance of export dynamics and possible changes to these dynamics under climate change, it is necessary to develop mechanistic and predictive models of planktonic ecosystems. Such models typically consist of a system of differential equations describing the temporal evolution of ecosystem variables (e.g. nutrients, phytoplankton, zooplankton (Fasham, 1993)). Real planktonic systems involve a large number of species displaying a bewildering complexity of physiological states, nutrient requirements, and trophic interactions. In planktonic ecosystem models, one is not able to model this complexity: rather, phytoplankton and zooplankton are divided into what are termed 'functional groups', defined by common ecosystem-scale characteristics.

Many formulations for modeling ecosystem dynamics have been proposed, and ecosystem models varying in complexity from 3 state variables (nutrient, phytoplankton (P), zooplankon $(\mathrm{Z})$ ) in a homogenous medium (e.g. Steele, 1974) to 3dimensional models containing multiple functional groups of plankton and nutrients (e.g. Moore et al., 2004) have been studied. In addition, many comprehensive global climate models that are used to study climate change have an ocean biology component that includes a simple planktonic ecosystem model (e.g. Schmittner et al., 2005, Zahariev et al., 2008). However, the dynamics of these ecosystem models are often poorly understood, particularly their response to a variable physical environment.

While the nonlinearity of these model equations generally limits the analytical study of model dynamics, useful insight can often be obtained through the study of local linearized dynamics around model equilibria (Perko, 2001). Continual physical forcing from the atmosphere and ocean mean that these ecosystems are never 
in steady state (Monahan and Denman, 2004, hereafter referred to as MD04). If variability is not too large, the state of the ecosystem may be considered as a steady background state that is modified by some perturbation evolving according to locally linear dynamics. Such a linearization allows for a systematic analysis of the model dynamics for a small perturbation from steady state, and may provide qualitative information about the behaviour of perturbations that may not be considered "small". Locally linearized dynamics have been used to study the stability properties of model equilibria (e.g. Edwards and Brindley, 1999), but although it has been demonstrated that modelled phytoplankton populations can display rapid transient growth (e.g. Pitchford and Brindley, 1999, Truscott and Brindley, 1994), less attention has been paid to the dynamics of perturbations around steady states. The relationship between the evolution of ecosystems and export flux is complicated, and possibly counter-intuitive. Well established mathematical theory (e.g. Tziperman and Ioannou, 2002) may be used to determine perturbations to a steady state that lead to responses from the ecosystem that are "optimal" in some specified way, such as maximizing the export flux (rate of POC leaving the model domain). These perturbations represent small changes to an ecosystem state that may occur in response to external forcing by natural occurrences such as addition of iron by dust deposition, advection and mixing with an eddy that has a different concentration of state variables, or mixed layer depth variability in response to fluctuating atmospheric forcing.

This study considers the dynamics of a medium complexity (5 compartment) model, representative of the type of model currently being embedded in global climate 
models. It was designed to simulate ecosystem processes at Ocean Station $\mathrm{P}\left(50^{\circ} \mathrm{N}\right.$ $\left.145^{\circ} \mathrm{W}\right)$, a HNLC region located in the subarctic northeast Pacific, where spring and summertime photosynthetic growth is thought to be limited by micronutrients such as iron. In this region, small phytoplankton are dominant and tightly coupled with microzooplankton, and diatom blooms are observed only occasionally (Boyd and Harrison, 1999). A wealth of historical data exist, and Station P was the site of the Subarctic Ecosystem Response to Iron Enrichment Study (SERIES), a synthetic iron fertilization experiment (Boyd et al., 2004). The data show that chlorophyll remains approximately constant throughout the year despite considerable variability within the ecosystem (Wong et al., 1999). Most of the time, the ecosystem at Station P appears to be near, or fluctuating about, steady state, and thus this setting is ideal for the analysis of small perturbations to equilibrium.

While this model is a highly idealized representation of the natural ecosystem, it is representative of the type of model currently being embedded in global climate models, so its dynamics are of interest for their implications regarding the ecosystem and these complex global models. The model is presented in Section 2, ecosystem and export responses to perturbations are presented in Section 3, and results are discussed in Section 4. Model details and linear optimization theory are discussed in Appendixes A and B, respectively.

\section{Model}

The planktonic ecosystem model used in this study is based on MD04 (Figure 1), but set in a 0-dimensional physical framework, i.e., a uniform mixed layer of fixed 
depth. The ecosystem model is similar to those used in global models of the carbon cycle (e.g. Zahariev et al., 2008). There are 2 functional groups of phytoplankton; small $(\leq 20 \mu m)$ phytoplankton, including flagellates $\left(P_{1}\right)$, and large $(>20 \mu m)$ phytoplankton, mainly diatoms $\left(P_{2}\right)$. The phytoplankton are split into functional groups because small and large phytoplankton are grazed at different trophic levels, and $P_{2}$ are normally thought to be the most important contributor to export flux. Microzooplankton $\left(Z_{1}\right)$ are modeled explicitly, and are tightly coupled with their prey, which are small phytoplankton and dead organic matter, termed detritus $(D)$. Mesozooplankton $\left(Z_{2}\right)$ graze on larger prey items, which in this model are $P_{2}$ and $Z_{1}$; time scales for changes in $Z_{2}$ biomass are much longer than for phytoplankton and microzooplankton, and thus $Z_{2}$ is specified at the maximum value of the observed annual cycle (Goldblatt et al., 1999) in order to simulate summer conditions. The only nutrient explicitly modeled, and so the only potentially limiting nutrient in the model, is nitrogen $(N)$. A full mathematical description of the ecosystem model is given in Appendix A. Table 1 contains definitions of symbols that are frequently used in this study, including state variables.

Of the four steady states found for this model (Healey, 2008), only one steady state is stable (Table 2), that is, small perturbations to this equilibrium will result in a return to this state. It also corresponds to a reasonable representation of conditions at Station P. While this steady state is asymptotically stable, some perturbations may display growth over finite times. The perturbation dynamics around this equilibrium will be the focus of this study. Perturbations (of initial magnitude $1 \mathrm{mmolNm}^{-3}$ ) that optimize export flux from the ecosystem are solved for (see 
Appendix B for methods), and responses to perturbations that display the highest export flux, relative to the initial export flux, are presented and discussed in Section 3. Note that because we consider the linearized model dynamics, the evolution of the perturbations is insensitve to the initial perturbation magnitude.

There are 3 pathways for the export of particulate matter from the ecosystem: sinking $D$ (with no aggregation), flux to higher trophic levels as $P_{2}$ and $Z_{1}$ are grazed upon by $Z_{2}$, and aggregation of $P_{2}$ and $D$ (Figure 1 bold arrows, (10). The third export pathway simulates the formation of marine snow in which larger phytoplankton and detritus form aggregates, which then sink (Alldredge and Silver, 1988). Also note the implicit assumption that the matter going to higher trophic levels does not re-enter the surface layer of the ocean once it leaves.

Note that the analyses in this study consider only export of particulate organic carbon and neglect contributions of dissolved organic carbon to export flux. This assumption is reasonable as a first approximation; sediment trap data suggests that POC is the greatest contributor to export flux at $20 \mathrm{~m}$ at Station $\mathrm{P}$ (Wong et al., 1999).

The sinking $D$ export flux depends linearly on $D$; however, the flux to higher trophic levels and aggregation terms are nonlinear and so must be linearized about the steady state in order to perform the optimizations (Appendix B). The linearized export in this case is given by

$$
\text { Export }=0.22 P_{2}+0.21 Z_{1}+0.38 D
$$




\section{Results: Ecosystem and Export Flux Responses to Perturbations a. Export flux}

As discussed in Appendix B, we determine unit perturbations (initially unit norm changes in state variables) to a model steady state that optimize the instantaneous export fluxes at specified times $\tau$. These "optimal perturbations" are calculated 10 times per day for fixed times between 0 and 30 days, so that there is sufficient resolution to observe the dependence of optimal perturbations on optimization time. Of the perturbations that optimize instantaneous export flux, the perturbation that results in the largest amplification (maximum instantaneous export flux relative to the initial export flux; given by (21)) is the perturbation that optimizes the export flux for $\tau=9.3$ days, with a maximum amplification factor of 12.5 (Figure 2). The set of changes to the state variables in this case is referred to as $\Phi_{F L U X}$, and its components are given in Table 3.

i. Ecosystem Response. The linearized response to $\Phi_{F L U X}$ is shown in Figure 4a. This initial perturbation consists primarily of an increase in $P_{2}$ (Table 3), that monotonically decreases, taking 75 days to drop to $10 \%$ of its initial value, and a decrease in $Z_{1}$ that allows a rapid bloom of $P_{1}$ which peaks at day 6 .

The $Z_{1}$ recover due to the abundance of available food, reaching maximum biomass at day 11 . The $P_{1}$ are then grazed below steady state value to a minimum at day 17 , which leads to a local minimum of $Z_{1}$ occurring at day 22. Damped predator-prey oscillations (Volterra, 1928) continue to occur with a period of 22-23 days, with the $P_{1}$ leading the $Z_{1}$ by 5-6 days. Because the model has more than two 
dimensions, predator-prey oscillations are not required to be about steady state; for most of the evolution of the perturbation, the $P_{1}$ remain above steady state value as the ecosystem approaches equilibrium, while $Z_{1}$ biomass oscillates about the steady state. The initial perturbation in $P_{1}$ is negligible, so that $P_{1}$ and $Z_{1}$ are synchronized relative to their predator-prey oscillation cycle with a lag of 5 days, allowing the maximum response in $P_{1}$.

Detritus biomass, and thus export flux of sinking $D$, reaches a maximum at 9 days, after the initial $P_{1}$ bloom peaks but before the $Z_{1}$ attain their maximum. This maximum of $D$ occurs before the peak $Z_{1}$ for 2 reasons: a portion of the increased $P_{1}$ being grazed down by $Z_{1}$ enters the $D$ pool via 'sloppy feeding', and there is less grazing of $Z_{1}$ on $D$ at this time (4).

There is considerable drawdown in $N(2-3 \mu M)$ with the concentration decreasing to a minimum of less than $6 \mu M$ at 68.5 days (not shown). This decay in $N$ results from the balance between $P_{2}$ uptake, with a long decay time, and the slow, steady supply of $N$ from below. After this time, $N$ concentrations begin to increase, albeit slowly, taking over a year to approach the former steady state value. In fact, the model dynamics governing incoming $N$ are unrealistic: all $N$ recovery is through upwelling and diffusion, as the model does not include horizontal mixing of nutrients. Furthermore, the model is set in a perpetual summer, with no winter deepening of the mixed layer. However, because the ecosystem is not $N$ limited at any time, the $N$ dynamics have no effect on the other state variables or export dynamics, which is the primary focus of this analysis. 
ii. Export Response. All components of export flux increase initially in response to $\Phi_{F L U X}$ (Figure 5a). Export flux due to aggregation reaches a maximum at day 6, after the maximum in $P_{2}$ and before the maximum in $D$, and then decreases toward steady state. Export to higher trophic levels reaches a maximum at day 10, and net export increases to a maximum shortly before day 10 , reflecting a compromise between export due to sinking $D$ and flux to higher trophic levels. These maxima follow the maximum in $P_{1}$; increased grazing on $P_{1}$ produces $D$, which sinks and contributes to aggregation, and the increased $Z_{1}$ biomass increases the flux to higher trophic levels. The maximum aggregation occurs earliest, before $P_{2}$ mortality increases due to increased grazing of $Z_{2}$ on $Z_{1}$. There is a second peak in export flux around day 30, and export fluxes display damped oscillations on the time scale of predator-prey interactions, in response to these oscillations in $P_{1}$ and $Z_{1}$.

Both major export events follow blooms in $P_{1}$. The maximum instantaneous export flux is $4.4 \mathrm{mmolNm} \mathrm{m}^{-2} \mathrm{~d}^{-1}$ (Table 4), the highest instantaneous export flux in response to any of the perturbations. Note that by construction, $\Phi_{F L U X}$ is the perturbation that gives the highest export flux relative to the initial export flux of the perturbation, with an amplification factor of 12.5 (Figure 6). The additional integrated export above steady state in response to this perturbation is $76 \mathrm{mmolNm}^{-2}$ $\left(6.1 \mathrm{~g} \mathrm{Cm}^{-2}\right.$ assuming a C:N ratio of 106:16, see Appendix A) over 150 days. Aside from the initial decreased flux of sinking detritus, all export rates remain above steady state export rates, primarily because $P_{1}$ and $P_{2}$ remain above their mean values. 


\section{b. Export flux, perturbation in $P_{1}$ and $P_{2}$}

In the previous subsection, the optimal perturbations were permitted to involve all components of the ecosystem, and all model state variables were involved in mediating the responses to this perturbation. In particular, interactions between $P_{1}$ and $Z_{1}$ were seen to be an important aspect of the response. It is natural to ask how large a response can be generated from a perturbation in only the phytoplankton, such as a bloom. Thus, for this optimization (Appendix B), only perturbations in $P_{1}$ and $P_{2}$ were allowed, while $Z_{1}, D$, and $N$ were held constant.

In this situation the amplification of the instantaneous export was much smaller than for $\Phi_{F L U X}$. The perturbation that optimizes export flux at $\tau=4.3$ days results in the maximum amplification of export flux by a factor of only 1.5. Although this amplification factor is small compared to the amplification of $\Phi_{F L U X}$, instantaneous export still increases by more than $50 \%$ above the initial perturbation.

i. Ecosystem Response. The ecosystem response to $\Phi_{F L U X-P}$ is shown in Figure 4b. This perturbation is an increase in both $P_{1}$ and $P_{2}$ (Table 3 ). The $P_{2}$ decay time scale is slightly shorter than in response to $\Phi_{F L U X}$; perturbed $P_{2}$ take 73 days to decay to $10 \%$ of the initial perturbation. The response to this perturbation is very similar to the response to $\Phi_{F L U X}$ but shifted by about 6 days; like $\Phi_{F L U X}$, damped predator-prey oscillations follow the perturbation, with $P_{1}$ remaining above steady state and $Z_{1}$ fluctuating about steady state. The microzooplankton abundance $Z_{1}$ increases in response to the increase in $P_{1}$, reaching a maximum at 5 days. Detritus increases to a maximum at 4.3 days due to both sloppy feeding by $Z_{1}$ as the $P_{1}$ are 
grazed down and to mortality of $P_{2}$. The $N$ concentration decreases to a minimum around 70.5 days, and then gradually begins to recover.

ii. Export Response. All components of export flux increase immediately following $\Phi_{F L U X-P}$ (Figure 5b). The net export flux reaches a maximum at 4 days. While the export flux is dominated by flux to higher trophic levels, the magnitude of this flux decreases following the perturbation; sinking detritus increases significantly following the initial perturbation, and is the main contributor to the amplification of export. The initial perturbation does not change the amount of $D$ present in the ecosystem, but increased $D$ due to $Z_{1}$ grazing on $P_{1}$, and $P_{2}$ mortality, result in additional export of sinking $D$, to a maximum at 4 days. Although the maximum amplification factor in the case of $\Phi_{F L U X-P}$ is much smaller than in $\Phi_{F L U X}$, the additional integrated export response to $\Phi_{F L U X-P}$ of $75 \mathrm{mmolNm}^{-2}\left(5.7 \mathrm{gCm}^{-2}\right)$ is only slightly less (Table $4)$.

c. Integrated flux

In the previous sections, instantaneous export flux was optimized at fixed times. These optimal perturbations may have little influence on the total amount of POC exported, as there is no guarantee that the transient export fluxes remain high as the ecosystem returns to equilibrium. The unit perturbation that maximizes the integrated export, i.e., the total amount of POC exported from the ecosystem as it returns to equilibrium, $\Phi_{I N T}$, is determined as presented in Appendix B. 
i. Ecosystem Response. The linearized ecosystem response to the perturbation $\Phi_{I N T}$ is shown in Figure 4c. This perturbation is primarily an increase in $P_{2}$ (Table 3). The other components of the initial perturbation conditions have a negligible effect on the ecosystem and export response; the responses to $\Phi_{I N T}$ are nearly indistinguishable from the responses to a perturbation that only increases $P_{2}, \Phi_{P_{2}}$ (Table 4). This initial increase in $P_{2}$ decays slowly, taking more than 75 days to drop below $10 \%$ of its initial value.

As the perturbation evolves, the initial slight decrease in $Z_{1}$ is amplified and the $Z_{1}$ biomass reduced significantly below equilibrium value to a minimum at 4.5 days. The increase in $P_{2}$ increases the overall grazing rate of $Z_{2}$, causing this decrease in $Z_{1}$. This response differs from the $Z_{1}$ increase observed following $\Phi_{F L U X}$ because $\Phi_{I N T}$ has almost no $P_{1}$ component, so there is no initial increase in flux to $Z_{1}$ biomass to offset the increased $Z_{2}$ grazing. The decrease in $Z_{1}$ results in less predation on $P_{1}, D$, and $P_{2}$ (indirectly), and allows an increase in $P_{1}$ that peaks at 9.6 days. This bloom increases the food availability of the $Z_{1}$, which respond by recovering to above-steady state values, peaking at 15.8 days. Like the response to $\Phi_{F L U X}$, damped predatorprey oscillations continue in $P_{1}$ and $Z_{1}$. At no time does the $P_{1}$ biomass drop below steady state, while the $Z_{1}$ biomass oscillates about its equilibrium value. Detritus values reach a maximum at 12.0 days.

ii. Export Response. The perturbation $\Phi_{I N T}$ is primarily an increase in $P_{2}$, which results in an immediate increased flux to higher trophic levels, and thus net export (Figure 5c). The increased flux to higher trophic levels ( $Z_{2}$ grazing) results in a decrease of $Z_{1}$, and a local minimum of both flux to higher trophic levels and net 
export. Damped oscillations driven by the predator-prey cycle between $Z_{1}$ and $P_{1}$ follow. Following the maxima caused by the initial $P_{1}$ bloom, all export components decrease. At no time do any of the export rates drop below steady state values.

The perturbation $\Phi_{I N T}$, results in additional integrated export of $93 \mathrm{mmolNm} \mathrm{m}^{-3}$ $\left(7.4 \mathrm{gCm}^{-2}\right.$, Table 4$)$ about $20 \%$ greater than that of $\Phi_{F L U X}$. The maximum export flux occurs at the time of perturbation, i.e., the maximum instantaneous amplification factor is less than 1 . As in the response to $\Phi_{F L U X}$, the slow decay of $P_{2}$, which is exported to higher trophic levels, is the primary reason for the large integrated export.

\section{d. Non-optimal perturbation: Proportional increase in $P_{1}$ and $P_{2}$}

The optimal perturbation in only $P_{1}$ and $P_{2}, \Phi_{F L U X-P}$, resulted in increased integrated export from the ecosystem relative to steady state (Table 4), and was primarily an increase in $P_{2}$. To investigate the dependence of perturbation evolution on initial conditions of our choosing, we consider an instantaneous bloom in both functional groups, $\Phi_{P_{1} P_{2}}$, represented by an increase in both $P_{1}$ and $P_{2}$ proportional to the phytoplankton steady state values (Table 3). Many conditions that improve conditions for photosynthesis for one phytoplankton functional group will similarly benefit other groups and also increase their growth rates, potentially resulting in an initial increase in both size classes proportional to steady state values. This perturbation is not the result of any optimization problem, but is considered for comparison to the optimal perturbations. 
i. Ecosystem Response. The linearized ecosystem response to $\Phi_{P_{1} P_{2}}$, shown in Figure $4 \mathrm{~d}$, is dominated by the predator-prey oscillations between $Z_{1}$ and $P_{1}$. Unlike the responses to $\Phi_{I N T}$ and $\Phi_{F L U X}$, the $P_{1}$ and $Z_{1}$ both drop below steady state levels. The $P_{2}$ anomaly decays by $71 \%$ to a relative minimum at 11.7 days. Weak oscillations follow, driven by the predator-prey cycle in $P_{1}$ and $Z_{1}$ (which influences $Z_{2}$ grazing rates). $P_{2}$ values do not drop below their steady state value at any time, and it takes about 56 days for the perturbed $P_{2}$ to decrease to $10 \%$ of the initial perturbation.

The $N$ response to $\Phi_{P_{1} P_{2}}$ is much different than the responses to $\Phi_{F L U X}, \Phi_{F L U X-P}$, and $\Phi_{I N T}$, which by construction, optimized exports. Initially $N$ concentrations decrease as biological uptake exceeds incoming $N$ from upwelling, reaching a minimum at 4.1 days. This change in $N$ is much smaller than the response to previous perturbations. Afterwards, $N$ begins to increase rapidly while overall primary production decreases, reaching a maximum in excess of its steady state concentration at 14.0 days. Following this maximum, $N$ decreases to below equilibrium, as primary production again increases above steady state.

ii. Export Response. All of the export components initially increase following $\Phi_{P_{1} P_{2}}$ (Figure 5d), with a maximum overall amplification factor of 4.5, although this perturbation reduces export flux for short time intervals. The integrated export in response to $\Phi_{P_{1} P_{2}}$ is $19 \mathrm{mmolNm}^{-2}\left(1.5 \mathrm{gCm}^{-2}\right)$, considerably less than the other perturbations discussed so far (Table 4). The maximum export flux in response to $\Phi_{P_{1} P_{2}}$ is $3.8 m m o l N m^{-2} d^{-1}$, similar to the other perturbations, but unlike those previously discussed, the export flux oscillates around the steady state value 
of $1.8 m m o l N m^{-2} d^{-1}$, with a minimum export flux of $1.3 m m o l N m^{-2} d^{-1}$. This different behavior occurs because the $P_{2}$ contribution to increased export flux relative to steady state is not large enough to offset the decrease in $D$ and $Z_{1}$ contributions following the declines in $P_{1}$ blooms. These minima are responsible for the relatively low integrated export, which is $20 \%$ of the integrated export due to $\Phi_{I N T}$.

\section{e. Non-optimal perturbation: Increase in $P_{1}$ alone}

The perturbation $\Phi_{P_{1} P_{2}}$ is primarily an increase in $P_{1}$ (Table 3 ). Integrated export resulting from this perturbation is low compared to that from the optimal perturbations, which are primarily in $P_{2}$, and is not much higher than the integrated export from the ecosystem at steady state. This difference led us to investigate if increasing only $P_{1}$ results in feedbacks that actually reduce the integrated export below that which occurs when the ecosystem remains at steady state over an equal time period. Like $\Phi_{P_{1} P_{2}}$, this perturbation is not the result of an optimization, and will be referred to as $\Phi_{P_{1}}$.

The ecosystem response to this perturbation, shown in Figure 4e, initially resembles that of $\Phi_{P_{1} P_{2}}$, but at 7.4 days the $N$ anomaly becomes positive and remains slightly above zero as it decays. The concentration of $N$ decreases when primary production is above steady state, and increases during periods when primary production is below steady state. Because, in general, export flux is highest during and following periods of high primary production, $N$ concentration tends to decrease before periods of enhanced export flux and increase during periods of reduced export flux. 
The maximum instantaneous export flux in response to $\Phi_{P_{1}}$ is $3.5 m m o l \mathrm{Nm}^{-2} d^{-1}$ (Table 4), similar to the other perturbations, although the minimum export flux is the lowest at $0.9 \mathrm{mmolNm} \mathrm{m}^{-2} \mathrm{~d}^{-1}$. There is one major export event in response to $\Phi_{P_{1}}$ (Figure 5e), which is followed by a rapid decline in export flux. The integrated export in response to $\Phi_{P_{1}}$ is nearly the same as integrated export from an ecosystem in steady state over an equivalent time period (Table 4). A perturbation that increases only $P_{1}$ has effectively no impact on the net export.

\section{Discussion}

While there are significant differences in detail between the ecosystem responses to the different optimal and non-optimal perturbations considered in the previous section, these responses share a number of common features. In particular, the small phytoplankton and zooplankton $\left(P_{1}\right.$ and $\left.Z_{1}\right)$ are tightly coupled because of their similar specific growth rates. This tight coupling results in predator-prey cycles (in 5 dimensions, so these oscillations do not always orbit around the steady state as would be the case in a 2-dimensional system), and to indirect couplings between $P_{1}$ and $P_{2}$ mediated by the grazers. An increase in $P_{2}$ results in an increased mesozooplankton specific grazing rate such that the increased grazing pressure on $Z_{1}$ can lead to a decline in microzooplaknton biomass and a consequent increase in $P_{1}$. In contrast, an increase in $P_{1}$ will lead to an increase in $Z_{1}$ and therefore to a decrease in $P_{2}$ due to increased grazing pressure by $Z_{2}$.

For the optimal perturbations, the $P_{1}$ biomass remains near or above steady state, resulting in enhanced fluxes to higher trophic levels. For the perturbation maximising 
integrated export flux, $\Phi_{I N T}, Z_{1}$ biomass remains below or near steady state: the resulting reduction in grazing pressure on $P_{2}$ allows for a more persistent bloom and enhanced net export flux. Note that those perturbations optimizing instantaneous export flux $\left(\Phi_{F L U X}, \Phi_{F L U X-P}\right)$ are associated with strong oscillatory variability in the $P_{1}-Z_{1}$ sector; the resulting substantial "blooms" are responsible for the large instantaneous export fluxes. In contrast, the perturbation that optimizes integrated export $\left(\Phi_{I N T}\right)$ is much less variable. (Figure 5).

For both non-optimal perturbations, $\Phi_{P_{1} P_{2}}$ and $\Phi_{P_{1}}$, the magnitude of the predator prey oscillations is larger than was the case for the optimal perturbations, and $P_{1}$ and $D$ biomasses oscillate about steady state. The low $P_{2}$ biomass in these perturbations reduces grazing pressure of $Z_{2}$ on $Z_{1}$, allowing the microzooplankton to rapidly graze down the $P_{1}$ and terminate the bloom. The predator-prey cycles have a visible (but small) effect on $N$ concentrations.

Clearly, the choice of zooplankton grazing function results in unexpected relationships between state variables, and the mathematical formulation of these functions is not well constrained by observations (Gentleman et al., 2003). In the present model $Z_{1}$ are not allowed to graze on $P_{2}$; Denman et al. (2006) allow for this grazing pathway at a low preference. If this pathway were included in our model the relationships between the phytoplankton state variables could change. Furthermore, alternate formulations of the specific grazing rate could possibly eliminate some of the indirect relationships between planktonic classes not directly linked by a predator/prey relationship.

There are also similarities between the export responses to the optimal perturba- 
tions: all result in integrated export significantly above steady state (Table 4) such that the flux to higher trophic levels is the greatest contributor and aggregation is insignificant. The majority of export components remain above steady state in response to all optimal perturbations: anomalies in both $Z_{2}$ grazing on $P_{2}$, and sinking $D$ remain positive (Figure 5), and these fluxes are large enough to offset the decrease in $Z_{2}$ grazing when when $Z_{1}$ biomass ventures below steady state. The additional integrated export in response to $\Phi_{F L U X}$ and $\Phi_{F L U X-P}$ is $20 \%$ less than $\Phi_{I N T}$ (Table 4), suggesting that as long as the perturbation is largely an increase in $P_{2}$, the other components do not significantly decrease the achievable integrated export.

For both non-optimal perturbations $\left(\Phi_{P_{1} P_{2}}, \Phi_{P_{1}}\right)$, sinking $D$ and predation by $Z_{2}$ on $Z_{1}$ oscillate about steady state. Although increases in primarily $P_{1}$ result in export events with high instantaneous flux, the flux of $P_{2}$ to higher trophic levels is insufficient to offset these minima and keep net export above steady state.

The persistence of large phytoplankton has been found to be an important contributor to integrated export, both directly through sinking and grazing fluxes to $Z_{2}$, and indirectly through suppressing $Z_{1}$ biomass (through an increase in $Z_{2}$ specific grazing rate) allowing greater primary productivity by $P_{1}$. In nature, the $P_{2}$ decay time scales are likely to be much shorter due to dilution from advection and mixing. We note that our model setup is similar to that of GCMs, in that the horizontal resolution of these models is coarse relative to the physical exchanges being modelled. A consequence of the coarse resolution is that the importance of $P_{2}$ to export flux may be increased in the model relative to its importance in the natural system. Furthermore, the iron limitation parameter is held constant in this study, further in- 
creasing the persitence of $P_{2}$ blooms relative to those observed in nature (where iron limitation is not static). When iron limitation is considered in contemporary global biogeochemical models, iron limitation parameters vary spatially but not temporally (e.g. Zahariev et al., 2008), and it is possible that these models also overestimate primary production at some locations, and thus export.

It is generally believed that large phytoplankton are the primary contributor to export via flux to higher trophic levels and sinking particles (e.g. Michaels and Silver, 1988), even in conditions where primary production is dominated by small phytoplankton. In this model, small phytoplankton do not directly contribute to export flux (12), but $P_{1}$ do contribute to all components of export flux indirectly. A portion of $P_{1}$ that is grazed by the microzooplankton is not assimilated and becomes $D$, which sinks, forms aggregates, and is grazed on by $Z_{1}$. Some of the $P_{1}$ and $D$ biomass that is assimilated by $Z_{1}$ will be exported to higher trophic levels as $Z_{2}$ graze on $Z_{1}$. Our analysis is consistent with the findings of Richardson and Jackson (2007), who suggest that the relative contributions of all phytoplankton to export, directly and indirectly, are proportional to their net primary production, and the importance of small phytoplankton to export flux may be underestimated in current models.

Export flux due to aggregation of microphytoplankton and detritus was found to make a negligible contribution to export flux in this study. Of course, this conclusion depends on the fidelity with which the process of aggregation is modelled. We note that although the aggregation coefficient $w_{A}$ is small $\left(0.02 \mathrm{mmolN}^{-1} \mathrm{~m}^{3} \mathrm{~d}^{-1}\right)$, increasing this parameter to $0.1 \mathrm{mmol}^{-1} \mathrm{~m}^{3} d^{-1}$ (Ruiz et al., 2002) has a negligible effect 
on the ecosystem dynamics and optimal perturbations, and aggregation remains the smallest contributor to export flux (not shown).

In the analysis considered in this study, both the perturbation dynamics and perturbation export fluxes have been linearized. We tested the reasonableness of the assumption of locally linear dynamics by investigating the differences between the

linear and nonlinear dynamics for perturbations of norm $0.5 \mathrm{mmolNm}^{-3}$ (Healey, 2008). On the whole, the linearizations were qualitatively accurate approximations to the fully nonlinear dynamics, especially the linearization of export flux. Although there exists literature on nonlinear optimal perturbations (e.g. Mu et al., 2003), the analysis of linear responses to perturbations ensures that results are independent of perturbation magnitude.

\section{Conclusions}

This study has considered the response of an idealized planktonic ecosystem model to perturbations in the initial conditions. In particular, an analysis of the linearized dynamics around a stable steady state of the system, that is similar to obervations of the natural system, allowed the diagnosis of those initial perturbations which resulted in maximum amplification of instantaneous export flux and those which resulted in maximum net export over the duration of the perturbation. The following primary results were obtained:

- Perturbations to planktonic ecosystems may display dramatic transient growth, as measured by export flux, and a consideration of dynamics linearised locally around a steady stable state allows the computation of those perturbations 
which lead to the largest export response.

- There is no simple relationship between amplification, maximum instantaneous export flux, and integrated export flux. Some perturbations resulted in a high initial increase in export but did not have significant net export flux, others had large net flux but not strong amplification.

- This study reinforces the complexity of interactions between components even in a linearized model; important aspects of the ecosystem responses such as export flux were sensitive to the structure of the perturbations.

- The flux to higher trophic levels was the dominant export flux. This result could be partly an artifact of the ecosystem model, but it is consistent with new observational studies (Richardson and Jackson, 2007). The indirect contribution of small phytoplankton to export flux is comparable to the contribution of the large phytoplankton.

- This study reinforces the importance of $Z_{1}$ in modelled fluxes and trophic interactions due to its direct and indirect role in trophic transfers (see Results). In general, microzooplankton are poorly sampled and their role in observed ocean ecosystem is not well understood (relative to those of other components of the ecosystem). The results of this study provide further support for more detailed observation of this component of the ecosystem.

This analysis yields relationships between state variables that are not obvious. It would be useful to investigate how export dynamics would change were a different 
ecosystem model used, particularly a model with different grazing formulations and trophic interactions. Results could elucidate key differences between models and give an indication of the generality of the conclusions obtained with the present model. Another natural extension of this study would be to perform a similar analysis to an ecosystem model that includes different carbon compounds, and a functional group of calcifying phytoplankton. Furthermore, this model is set in the open ocean, and the parameters are tuned for a HNLC area where the effects of nutrient limitation are assumed constant. Because the ecosystem was not $N$ limited in steady state, the response of $N$ to perturbations did not affect the dynamics of other state variables. This type of analysis could be used to study the transient dynamics of other open ocean regions or coastal ecosystem models, which may be limited by $N$, and possibly other nutrients, and are subject to different sources of perturbations.

The response of this ecosystem model to perturbations provides insight into how planktonic ecosystems may respond to natural variability, and how ecosystem models may respond to a changing environment when coupled with GCMs. Because these models are being used to predict future climate scenarios, it is important to study their internal dynamics and the effects of these dynamics on carbon fluxes in ocean models.

Acknowledgments. The authors would like to thank the Natural Sciences and Engineering Research Council of Canada (NSERC), Fisheries and Oceans Canada, and the University of Victoria for funding. They would also like to thank Ken Denman and Andrew Edwards for their feedback and thoughtful comments. 


\section{Appendix A: Model Description}

The planktonic ecosystem model considers 2 functional groups of phytoplankton:

nanophytoplankton(flagellates, $P_{1}$ ) and microphytoplankton (diatoms, $P_{2}$ ), 2 functional types of zooplankton; microzooplankton $\left(Z_{1}\right)$ and mesozooplankton $\left(Z_{2}\right.$, which is specified), and detritus (D). The single prognostic nutrient is nitrogen (N), which is also the model currency. The evolution of these 5 state variables is given by the following set of differential equations:

$$
\begin{gathered}
\frac{d P_{1}}{d t}=\nu P_{1}-\gamma_{1} \frac{P_{1}}{P_{1}+p_{D} D} Z_{1} \\
\frac{d P_{2}}{d t}=\nu P_{2}-\gamma_{2} Z_{2} \frac{P_{2}}{P_{2}+Z_{1}}-m_{p d} P_{2}-w_{A}\left(P_{2}^{2}+\frac{2 P_{2}}{P_{2}+D} P_{2} D\right) \\
\frac{d Z_{1}}{d t}=g_{a} \gamma_{1} Z_{1}-\gamma_{2} Z_{2} \frac{Z_{1}}{P_{2}+Z_{1}}-m_{z a} Z_{1} \\
\frac{d D}{d t}=m_{p d} P_{2}+\left(1-g_{a}\right) \gamma_{1} Z_{1}-\gamma_{1} \frac{p_{D} D}{P_{1}+p_{D} D} Z_{1}-r_{e} D-w_{D} D-w_{A}\left(D^{2}+\frac{2 D}{P_{2}+D} P_{2} D\right) \\
\frac{d N}{d t}=-\nu\left(P_{1}+P_{2}\right)+r_{e} D+m_{z a} Z_{1}+m_{c a} \gamma_{2} Z_{2}+\frac{v_{U W}}{d_{M L}}\left(N_{0}-N\right)
\end{gathered}
$$

The parameter values used in this study are given in Table 5. The phytoplankton 
specific growth rate, $\nu$, is given by Liebig's law of the minimum:

$$
\nu=\nu_{\max } \min \left(\frac{N}{k_{n}+N}, L_{f e}\right)
$$

where $\nu_{\max }$ is the maximum growth rate in the absence of nutrient limitation and $k_{N}$ is a nitrogen half-saturation constant. When growth is not limited by $\mathrm{N}$, the parameter $L_{f e}$ sets an upper limit on phytoplankton growth that represents limitation of a micronutrient such as iron. Because the model is set in summer conditions, it is assumed that light is not limiting at any time.

The microzooplankton, $Z_{1}$, graze on both $P_{1}$ and $D$ with grazing rate

$$
\gamma_{1}=r_{m} \frac{\left(P_{1}+p_{D} D\right)^{2}}{k_{p}^{2}+\left(P_{1}+p_{D} D\right)^{2}}
$$

where $p_{D}$ is the relative grazing preference of $Z_{1}$ on $D$ over $P_{1}$ and $k_{p}$ is the "halfsaturation constant".

Mesozooplankton biomass is held fixed because $Z_{2}$ have relatively long life spans (order months to years) compared to $Z_{1}$, and biomass is unlikely to change in response to ecosystem changes on the time scales considered. However, the $Z_{2}$ grazing rate responds to changes in availability of $P_{2}$ and $Z_{1}$ :

$$
\gamma_{2}=r_{c} \frac{\left(P_{2}+Z_{1}\right)^{2}}{k_{z}^{2}+\left(P_{2}+Z_{1}\right)^{2}}
$$

The mortality rate of $P_{2}$ to $D, m_{p d}$, is linear. Aggregation, i.e. the formation of marine snow (Alldredge and Silver, 1988), is represented by a quadratic term in 
both $P_{2}$ and $D$. The assimilation efficiency of $Z_{1}$, i.e. the portion of grazed $P$ that is converted to $Z$ biomass, is denoted $g_{a}$; unassimilated matter, e.g. biomass lost to sloppy feeding, becomes $D$. Microzooplankton excrete $\mathrm{N}$ with specific rate $m_{z a}$. The particulate nitrogen contained in detritus is converted to dissolved nitrogen at the specific remineralization rate $r_{e}$, and $D$ sinks at rate $w_{D}\left(7.5 m d^{-1}\right)$. A portion of the biomass grazed by $Z_{2}$ is immediately excreted to $N$ at a rate of $m_{c a}$

Station P is located in the Alaskan Gyre, a region of weak upwelling (Pond and Pickard, 1983). Nitrogen is injected via upwelling and exchanged by mixing with water from below the mixed layer that has average nitrogen concentration $N_{0}$ at rate $v_{U W}$. Any dilution of other state variables by physical exchange is included in the linear growth and mortality rates. The physical parameters for the model are set to be broadly consistent with observations made at Station $\mathrm{P}$ in the summer, for those parameters for which these observations exist (Table 5).

Export from the ecosystem is given by the equation

$$
\text { Export }=w_{D} D+\gamma_{2} Z_{2}+w_{A}\left(P_{2}+D\right)^{2}
$$

The sinking $D$ export flux depends linearly on $D$, however the flux to higher trophic levels and aggregation terms are nonlinear and so must be linearized about the steady state in order to perform the optimizations described in Appendix B. The export function for the ecosystem state is approximated using a Taylor series expansion:

$$
\operatorname{Export}\left(\mathbf{x}_{0}+\Delta \mathbf{x}\right) \approx \operatorname{Export}\left(\mathbf{x}_{0}\right)+\nabla \operatorname{Export}\left(\mathbf{x}_{0}\right)^{T} \cdot \Delta \mathbf{x}
$$


where $\mathbf{x}_{0}$ is the ecosystem steady state, $\Delta \mathbf{x}$ the perturbation to this state, and $\nabla$ the gradient operator relative to the state variables. The linearized export is thus given by the equation

$$
\text { Export }=\operatorname{Export}\left(\mathbf{x}_{0}\right)+0.22 \Delta P_{2}+0.21 \Delta Z_{1}+0.38 \Delta D
$$

where $\Delta P_{2}, \Delta Z_{1}$, and $\Delta D$ are the perturbations in large phytoplankton, small zooplankton, and detritus, respectively. The export rates are computed in units of $m m o l N m^{-3} d^{-1}$ and a constant $\mathrm{C}: \mathrm{N}$ ratio is assumed for $P_{2}, Z_{1}$, and $D$, so comparing nitrogen export rates is equivalent to comparing the carbon export rate. The Redfield C:N ratio for phytoplankton of 106:16 is used (Redfield et al., 1963). Note that $\mathrm{C}: \mathrm{N}$ may vary in time and for different forms of organic matter in the ocean, but on average it is well approximated by the Redfield ratio. Variations in the ratio are not modelled because the added complexity is not warranted or well-constrained (Sterner and Elser, 2002).

\section{Appendix B: Optimal Perturbations}

The system of equations (2) - (6) can be expressed as the autonomous system of first order ordinary differential equations

$$
\frac{d \mathbf{x}}{d t}=\mathbf{f}(\mathbf{x})
$$

where $\mathbf{x}=\left(P_{1}, P_{2}, Z_{1}, D, N\right)$ is the state vector. The dynamics of a small perturbation around a fixed point $\mathbf{x}_{0}, \Delta \mathbf{x}=\mathbf{x}-\mathbf{x}_{0}$, can be described by the linearized dynamics 


$$
\frac{d}{d t} \Delta \mathbf{x}=\mathbf{A} \Delta \mathbf{x}
$$

where $\mathbf{A}$ is the Jacobian of $\mathbf{f}(\mathbf{x})$ evaluated at $\mathbf{x}_{0}$, that is

$$
A_{i, j}=\left.\frac{\partial f_{i}(\mathbf{x})}{\partial x_{j}}\right|_{\mathbf{x}=\mathbf{x}_{0}}
$$

The solution of (14) is

$$
\Delta \mathbf{x}(t)=e^{A t} \Delta \mathbf{x}_{0}
$$

Provided that $\mathbf{x}$ remains sufficiently close to $\mathbf{x}_{0}$, the linearized dynamics will be a good approximation to the evolution of the full nonlinear system (Perko, 2001).

\section{a. Optimizing rates}

If the equilibrium $\mathbf{x}_{\mathbf{0}}$ is stable, then the real parts of the eigenvalues of $\mathbf{A}$ will all be negative and small perturbations to a stable steady state will eventually converge back to equilibrium. However, these perturbations may display transient growth over finite times if the matrix $\mathbf{A}$ is not normal (i.e. $\mathbf{A} \mathbf{A}^{T} \neq \mathbf{A}^{T} \mathbf{A}$, where $\mathbf{A}^{T}$ is the transpose of $\mathbf{A}$ (Farrell and Ioannou, 1996)). It is possible to solve for the perturbation that optimizes some measure of the size of the perturbation at a fixed time $\tau$, subject to the constraint that the perturbation be of unit norm (under some metric) at time $t=0$ (Tziperman and Ioannou, 2002). Let $\mathbf{R}$ be a matrix defining the perturbation norm to be optimized, so that the magnitude of the perturbation at time $\tau$ is given by 


$$
J(t)=\Delta \mathbf{x}_{0}^{T}\left(e^{A \tau}\right)^{T} \mathbf{R} e^{A \tau} \Delta \mathbf{x}_{0}
$$

The optimal perturbation at time $\tau$ is defined as the initial perturbation $\Delta \mathbf{x}_{0}$ that maximizes $J(\tau)$ under the norm $\mathbf{R}$, subject to the constraint that the norm of this perturbation is unity under some nonsingular norm $\mathbf{S}$ :

$$
\Delta \mathbf{x}_{0}^{T} \mathbf{S} \Delta \mathbf{x}_{0}=1
$$

It follows from this constrained optimization problem that the optimal perturbations satisfy the generalized eigenvalue problem

$$
\left(e^{A \tau}\right)^{T} \mathbf{R} e^{A \tau} \Delta \mathbf{x}_{0}=\lambda \mathbf{S} \Delta \mathbf{x}_{0}
$$

where $\lambda$ is a Lagrange multiplier. That is, the eigenvector corresponding to the largest eigenvalue of the matrix

$$
\mathbf{S}^{-1}\left(e^{A \tau}\right)^{T} \mathbf{R} e^{A \tau}
$$

will be the optimal perturbation at time $\tau$ under the norm $\mathbf{R}$. As the perturbation evolves, the amplification of the perturbation under $\mathbf{R}$ is defined as

$$
A m p^{2}(t)=\frac{\Delta \mathbf{x}(t)^{T} \mathbf{R} \Delta \mathbf{x}(t)}{\Delta \mathbf{x}_{0}^{T} \mathbf{R} \Delta \mathbf{x}_{0}}
$$

In this study, the norm $\mathbf{R}$ is the matrix containing the coefficients of the squared linear export flux (12). The instantaneous export flux is optimized subject to the 
constraint that the initial biomass of the perturbation is unity. For the perturbation in all state variables, $\Phi_{F L U X}, \mathbf{S}$ is the identity matrix, and for $\Phi_{F L U X-P}$, entries involving state variables other than $P_{1}$ and $P_{2}$ are large to suppress contributions of the other state variables.

\section{b. Optimizing integrated quantities}

The above theory is used to optimize the magnitude of the instantaneous state of a system of equations under some measure. Because of the potential of planktonic ecosystems as carbon sinks, it is of interest to determine the perturbation that results in the maximum carbon export over some period of time, that is, the integrated export. Maximizing the instantaneous export flux is equivalent to maximizing its square (17). However, the perturbation that optimizes the integral of the squared export flux does not necessarily result in the highest integrated export (which might involve some cancellation between positive and negative anomalies in export flux), so a different approach is required. The previous optimization problem involves a bilinear operator in the state vector, whereas this problem optimizes a dot product, and is linear in the state vector .

It is possible to determine the unit perturbation $\Delta \mathbf{x}_{0}$ that maximizes the integral of the projection of the model state on some vector $\mathbf{y}=\left(y_{1}, y_{2}, \ldots, y_{n}\right)$, where $\mathrm{n}$ is the dimension of the model. The quantity to be optimized is

$$
I=\int_{0}^{\infty} \mathbf{y} \cdot e^{A t} \Delta \mathbf{x}_{0} d t \approx \Delta t \sum_{\tau=0}^{\infty} \mathbf{y} \cdot e^{A \tau \Delta t} \Delta \mathbf{x}_{0}
$$


where $\Delta t$ is the timestep. Thus, the quantity to be maximized is

$$
\Delta t \sum_{\tau=0}^{\infty} \mathbf{y} \cdot e^{A \tau \Delta t} \Delta \mathbf{x}_{0}+\lambda\left(\Delta \mathbf{x}_{0}^{T} \mathbf{S} \Delta \mathbf{x}_{0}-1\right)
$$

where $\lambda$ is a Lagrange multiplier, and $\mathbf{S}$ is the identity matrix, as in Section 3a. Let $M(\tau)=e^{A \tau \Delta t}$. Evaluating the dot product and setting the derivative with respect to $\Delta \mathbf{x}_{0}$ to 0 gives

$$
\Delta \tilde{x}_{0 j}=\sum_{\tau=1}^{\infty} \sum_{i=1}^{n} y_{i} M_{i, j}(\tau)
$$

Setting

$$
\mathbf{x}_{0}=\frac{1}{\left|\Delta \tilde{\mathbf{x}}_{0}\right|} \Delta \tilde{\mathbf{x}}_{0}
$$

gives an initial perturbation of norm 1 .

Note that optimizing the integrated export over the interval $[\tau-\Delta, \tau+\Delta]$ is equivalent to optimizing the instantaneous export flux at time $\tau$ as $\Delta \rightarrow 0$. 


\section{References}

Alldredge, A. and M. Silver. 1988. Characteristics, dynamics and significance of marine snow. Progress in Oceanography, 20, $41-82$.

Archer, D., S. Emerson, T. Powell, and C. Wong. 1993. Numerical hindcasting of sea surface $\mathrm{pCO}_{2}$ at weathership Station Papa. Progress in Oceanography, 32, $319-351$.

Boyd, P. and P. Harrison. 1999. Phytoplankton dynamics in the ne subarctic pacific. Deep-Sea Research Part II: Topical Studies in Oceanography, 46, $2405-2432$.

Boyd, P. W., C. S. Law, C. S. Wong, Y. Nojiri, A. Tsuda, M. Levasseur, S. Takeda, R. Rivkin, P. J. Harrison, R. Strzepek, J. Gower, R. M. McKay, E. Abraham, M. Arychuk, J. Barwell-Clarke, W. Crawford, D. Crawford, M. Hale, K. Harada, K. Johnson, H. Kiyosawa, I. Kudo, A. Marchetti, W. Miller, J. Needoba, J. Nishioka, H. Ogawa, J. Page, M. Robert, H. Saito, A. Sastri, N. Sherry, T. Soutar, N. Sutherland, Y. Taira, F. Whitney, S. K. E. Wong, and T. Yoshimura. 2004. The decline and fate of an iron-induced subarctic phytoplankton bloom. Nature, 428, 549-553.

de Baar, H., P. Boyd, K. Coale, M. Landry, A. Tsuda, P. Assmy, D. Bakker, Y. Bozec, R. Barber, M. Brzezinski, K. Buesseler, M. Boye, P. Croot, F. Gervais, M. Gorbunov, P. Harrison, W. Hiscock, P. Laan, C. Lancelot, C. Law, M. Levasseur, A. Marchetti, F. Millero, J. Nishioka, Y. Nojiri, T. van Oijen, U. Riebesell, M. Rijkenberg, H. Saito, S. Takeda, K. Timmermans, M. Veldhuis, A. Waite, and C.-S. 
Wong. 2005. Synthesis of iron fertilization experiments: From the iron age in the age of enlightenment. Journal of Geophysical Research Part C., 110, 1-24.

Denman, K. and M. Pena. 2002. The response of two coupled one-dimensional mixed layer/planktonic ecosystem models to climate change in the NE subarctic Pacific Ocean. Deep-Sea Research Part II: Topical Studies in Oceanography, 49, 57395757.

Denman, K. L., C. Voelker, M. A. Pena, and R. B. Rivkin. 2006. Modelling the ecosystem response to iron fertilization in the subarctic NE Pacific: The influence of grazing, and Si and N cycling on CO2 drawdown. Deep-Sea Research Part II: Topical Studies in Oceanography, 53, 2327-2352.

Edwards, A. M. and J. Brindley. 1999. Zooplankton mortality and the dynamical behaviour of plankton population models. Bulletin of Mathematical Biology, 61, 303-339.

Farrell, B. and P. Ioannou. 1996. Generalized stability theory. Part 1: Autonomous operators. Journal of the Atmospheric Sciences, 53, 2025-2040.

Fasham, M. J. R. 1993. Modelling the marine biota. In Heimann, M., ed., The Global Carbon Cycle. Springer-Verlag, volume 73 Supp., pp. 457-504.

Gentleman, W., A. Leising, B. Frost, S. Strom, and J. Murray. 2003. Functional responses for zooplankton feeding on multiple resources: a review of assumptions and biological dynamics. Deep-Sea Research Part II: Topical Studies in Oceanography, $50,2847-2875$. 
Goldblatt, R. H., D. L. Mackas, and A. G. Lewis. 1999. Mesozooplankton community characteristics in the NE subarctic Pacific. Deep-Sea Research Part II: Topical Studies in Oceanography, 46, 2619-2644.

Healey, K. 2008. Perturbation dynamics of a planktonic ecosystem. Master's thesis, University of Victoria.

Jo, C. O., J. Y. Lee, K. A. Park, Y. H. Kim, and K. R. Kim. 2007. Asian dust initiated early spring bloom in the northern East/Japan Sea. Geophysical Research Letters, 34.

Martin, J., R. Gordon, and S. Fitzwater. 1991. The case for iron. Limnology \& Oceanography, 36, $1793-1802$.

Martin, J., R. Gordon, S. Fitzwater, and W. Broenkow. 1989. VERTEX: Phytoplankton/iron studies in the Gulf of Alaska. Deep-Sea Research Part A., 36, 649-680.

Michaels, A. F. and M. W. Silver. 1988. Primary production, sinking fluxes and the microbial food web. Deep-Sea Research Part A-Oceanographic Research Papers, 35, 473-490.

Monahan, A. and K. Denman. 2004. Impacts of atmospheric variability on a coupled upper-ocean/ecosystem model of the subarctic Northeast Pacific. Global Biogeochemical Cycles, 18. GB2010, doi:10.1029/2003GB002100.

Moore, J. K., S. C. Doney, and K. Lindsay. 2004. Upper ocean ecosystem dynam- 
ics and iron cycling in a global three-dimensional model. Global Biogeochemical Cycles, 18, 1-21.

Mu, M., W. S. Duan, and B. Wang. 2003. Conditional nonlinear optimal perturbation and its applications. Nonlinear Processes in Geophysics, 10, 493-501.

Perko, L. 2001. Differential Equations and Dynamical Systems. Springer-Verlag, 538 pp.

Pitchford, J. W. and J. Brindley. 1999. Iron limitation, grazing pressure and oceanic high nutrient-low chlorophyll (HNLC) regions. Journal of Plankton Research, 21, $525-547$.

Pond, S. and G. L. Pickard. 1983. Introductory Dynamical Oceanography. Butterworth-Heinemann, 349 pp.

Redfield, A. C., B. H. Ketchum, and F. A. Richards. 1963. The influence of organisms on the composition of sea-water. In Hill, M., ed., The sea: Ideas and observations on progress in the study of the seas. John Wiley and Sons, New York, pp. 26-77.

Richardson, T. L. and G. A. Jackson. 2007. Small phytoplankton and carbon export from the surface ocean. Science, 315, 838-840.

Ruiz, J., L. Prieto, and F. Ortegon. 2002. Diatom aggregate formation and fluxes: a modeling analysis under different size-resolution schemes and with empirically determined aggregation kernels. Deep-sea Research Part I-Oceanographic Research Papers, 49, 495-515. 
Saito, H., A. Tsuda, Y. Nojiri, J. Nishioka, S. Takeda, H. Kiyosawa, I. Kudo, Y. Noiri, T. Ono, Y. Taira, K. Suzuki, T. Yoshimura, and P. W. Boyd. 2006. Nutrient and phytoplankton dynamics during the stationary and declining phases of a phytoplankton bloom induced by iron-enrichment in the eastern subarctic pacific. DeepSea Research Part II: Topical Studies in Oceanography, 53, 2168-2181.

Sarmiento, J. L. and N. Gruber. 2006. Ocean Biogeochemical Dynamics. Princeton University Press, 526 pp.

Schmittner, A., A. Oschlies, X. Giraud, M. Eby, and H. Simmons. 2005. A global model of the marine ecosystem for long-term simulations: Sensitivity to ocean mixing, buoyancy forcing, particle sinking, and dissolved organic matter cycling. Global Biogeochemical Cycles, 19, 1-17.

Steele, J. 1974. The Structure of Marine Ecosystems. Harvard University Press, 128 pp.

Sterner, R. W. and J. J. Elser. 2002. Ecological Stoichiometry: The Biology of Elements from Molecules to the Biosphere. Princeton University Press, 584 pp.

Truscott, J. E. and J. Brindley. 1994. Ocean plankton populations as excitable media. Bulletin of Mathematical Biology, 56, 981-998.

Tziperman, E. and P. J. Ioannou. 2002. Transient growth and optimal excitation of thermohaline variability. Journal of Physical Oceanography, 32, 3427 - 3435.

Volk, T. and M. Hoffert. 1985. Ocean carbon pumps - Analysis of relative strengths and efficiencies in ocean-driven atmospheric CO2 changes. In Sundquist, E. and 
W. Broecker, eds., The Carbon Cycle and Atmospheric $\mathrm{CO}_{2}$ : Natural variations Archean to Present, AGU, Washington, D.C., volume 32 of Geophysical Monograph Series. pp. 99-110.

Volterra, V. 1928. Variations and fluctuations of the number of individuals in animal species living together. ICES Journal of Marine Science, 3, 3-51.

Whitney, F. and H. Freeland. 1999. Variability in upper-ocean water properties in the NE Pacific Ocean. Deep-Sea Research Part II: Topical Studies in Oceanography, 46, 2351-2370.

Wong, C. S., D. A. Timothy, C. S. Law, Y. Nojiri, L. S. Xie, S. K. E. Wong, and J. S. Page. 2006. Carbon distribution and fluxes during the SERIES iron fertilization experiment with special reference to the fugacity of carbon dioxide $(\mathrm{fCO}(2))$. DeepSea Research Part II: Topical Studies in Oceanography, 53, 2053-2074.

Wong, C. S., F. A. Whitney, D. W. Crawford, K. Iseki, R. J. Matear, W. K. Johnson, and J. S. Page. 1999. Seasonal and interannual variability in particle fluxes of carbon, nitrogen and silicon from time series of sediment traps at Ocean Station P, 1982-1993: relationship to changes in subarctic primary productivity. Deep-Sea Research Part II: Topical Studies in Oceanography, 46, 2735-2760.

Zahariev, K., J. Christian, and K. Denman. 2008. A global ocean carbon model with novel parameterizations of iron limitation, calcification and N2 fixation: preindustrial, historical, and fertilization simulations. Progress in Oceanography, 77, $56-82$. 
Table 1. Definition of frequently used symbols. Each $\Phi$ represents a perturbation experiment.

Table 2. Ecosystem state variable values for the only stable steady state of the 4 steady state solutions possible.

Table 3. Unit perturbations $\left(\mathrm{mmolNm}^{-3}\right)$ to steady state. The perturbation $\Phi_{F L U X}$ is in all state variables, optimizes instantaneous export flux, and gives high transient amplification. The perturbation $\Phi_{F L U X-P}$ is only in phytoplankton state variables, optimizes instantaneous export flux, and results in significant amplification. The perturbation $\Phi_{I N T}$ optimizes integrated export flux. The perturbations $\Phi_{P_{2}}, \Phi_{P_{1} P_{2}}$, and $\Phi_{P_{1}}$ are considered for comparison to the optimal perturbations

Table 4. Properties of export responses to perturbations: minimum and maximum export flux, and integrated export over 150 days ( $1 \mathrm{hr}$ timestep) in response to perturbations, for perturbation of magnitude $0.5 \mathrm{mmolNm} \mathrm{m}^{-3}$. The values in Column 4 are calculated using a Redfield ratio of 106:16 C:N. Export fluxes are obtained by multiplying export per unit volume by mixed layer depth $(20 \mathrm{~m})$. Column 5 represents the $P_{2}$ decay time.

Table 5. Model parameter values. Many ecosystem parameters have been tuned to agree with observations and are not well constrained. MD04=Monahan and Denman (2004), DP02=Denman and Pena (2002), W99=Whitney and Freeland (1999), A93= Archer et al. (1993) , CV=C. Voelker, pers. com., P-Hist=Station P historical data, Institute of Ocean Sciences Archive 


\begin{tabular}{|l|c|}
\hline$t$ & Time \\
\hline$P_{1}$ & Small phytoplankton $(\leq 20 \mu \mathrm{m})$ \\
\hline$P_{2}$ & Large phytoplankton $(>20 \mu \mathrm{m})$ \\
\hline$Z_{1}$ & Microzooplankton \\
\hline$D$ & Detritus \\
\hline$N$ & Nitrogen \\
\hline$Z_{2}$ & Mesozooplankton \\
\hline$\Phi_{F L U X}$ & Maximizes instantaneous export flux, amplification \\
\hline$\Phi_{F L U X-P}$ & Maximizes instantaneous export flux, amp.; restricted to $P_{1}$ and $P_{2}$ \\
\hline$\Phi_{I N T}$ & Maximizes integrated export \\
\hline$\Phi_{P_{2}}$ & Increase in only $P_{2}$ \\
\hline$\Phi_{P_{1} P_{2}}$ & Proportional increase in $P_{1}$ and $P_{2}$ \\
\hline$\Phi_{P_{1}}$ & Increase in only $P_{1}$ \\
\hline
\end{tabular}

Table 1.

\begin{tabular}{|l|l|l|l|l|}
\hline & \multicolumn{4}{|c|}{ steady state values $\left(\mathrm{mmolNm}^{-3}\right)$} \\
\hline$P_{1}$ & $P_{2}$ & $Z_{1}$ & $D$ & $N$ \\
\hline 0.5265 & 0.1105 & 0.4073 & 0.0919 & 8.3153 \\
\hline
\end{tabular}

Table 2.

\begin{tabular}{|l|l|l|l|l|l|}
\hline & $P_{1}$ & $P_{2}$ & $Z_{1}$ & $D$ & $N$ \\
\hline$\Phi_{F L U X}$ & 0.0785 & 0.8160 & -0.5641 & -0.0989 & -0.0005 \\
\hline$\Phi_{F L U X-P}$ & 0.6423 & 0.7665 & 0 & 0 & 0 \\
\hline$\Phi_{I N T}$ & -0.0009 & 0.9977 & -0.0296 & 0.0616 & -0.0040 \\
\hline$\Phi_{P_{2}}$ & 0 & 1.0000 & 0 & 0 & 0 \\
\hline$\Phi_{P_{1} P_{2}}$ & 0.9807 & 0.1955 & 0 & 0 & 0 \\
\hline$\Phi_{P_{1}}$ & 1.0000 & 0 & 0 & 0 & 0 \\
\hline
\end{tabular}

Table 3. 


\begin{tabular}{|c|c|c|c|c|c|}
\hline & \multicolumn{2}{|c|}{$\begin{array}{l}\text { export flux } \\
m m o l N m^{-2} d^{-1}\end{array}$} & \multirow[t]{2}{*}{$\begin{array}{l}\text { int. export } \\
\left(\mathrm{mmolNm}^{-2}\right)\end{array}$} & \multirow[t]{2}{*}{$\begin{array}{l}\text { int. export relative to } \\
\text { steady state }\left(\mathrm{gCm}^{-2}\right)\end{array}$} & \multirow[t]{2}{*}{$\begin{array}{l}\text { day such that } \\
\Delta P_{2}(t)=.1 \Delta P_{2}(0)\end{array}$} \\
\hline & $\min$ & $\max$ & & & \\
\hline$\Phi_{F L U X}$ & 2.0 & 4.4 & 350 & +6.1 & 75 \\
\hline$\Phi_{F L U X-P}$ & 1.9 & 4.4 & 350 & +5.7 & 73 \\
\hline$\Phi_{I N T}$ & 1.9 & 4.2 & 370 & +7.4 & 75 \\
\hline$\Phi_{P_{2}}$ & 1.9 & 4.1 & 370 & +7.4 & 75 \\
\hline$\Phi_{P_{1} P_{2}}$ & 1.3 & 3.8 & 300 & +1.5 & 56 \\
\hline$\Phi_{P_{1}}$ & 0.86 & 3.5 & 280 & +0.02 & NA \\
\hline Steady State & 1.8 & 1.8 & 280 & 0 & NA \\
\hline
\end{tabular}

Table 4.

\begin{tabular}{|l|l|l|l|l|}
\hline & & Value & Unit & Source \\
\hline$\nu_{m a x}$ & maximum phyto. growth rate & 1.5 & $d^{-1}$ & DP02 \\
\hline$p_{d}$ & grazing preference of $Z_{1}$ on $D$ & 0.5 & - & DP02 \\
\hline$Z_{2}$ & $Z_{2}$ biomass & 0.2 & $m m o l N m^{-3}$ & DP02 \\
\hline$m_{p d}$ & $P_{2}$ to $D$ mortality & 0.1 & $d^{-1}$ & MD04 \\
\hline$m_{z a}$ & $Z_{1}$ to $N$ & 0.1 & $d^{-1}$ & MD04 \\
\hline$r_{e}$ & $D$ remineralization rate & 0.1 & $d^{-1}$ & DP02 \\
\hline$m_{c a}$ & $Z_{2}$ grazing to $N$ & 0.3 & - & DP02 \\
\hline$r_{m}$ & maximum $Z_{1}$ grazing rate & 1.0 & $d^{-1}$ & DP02 \\
\hline$k_{p}$ & $Z_{1}$ grazing half-saturation const. & 0.75 & $m m o l N m^{-3}$ & DP02 \\
\hline$r_{c}$ & maximum $Z_{2}$ grazing rate & 6.5 & $d^{-1}$ & MD04 \\
\hline$k_{z}$ & $Z_{2}$ grazing half-saturation const. & 2 & $m m o l N m^{-3}$ & MD04 \\
\hline$N_{0}$ & average $N$ below mixed layer & 26.8 & $m m o l N m^{-3}$ & P-Hist \\
\hline$k_{n}$ & $P$ growth half-saturation const. & 0.1 & $m m o l N m^{-3}$ & DP02 \\
\hline$L_{f e}$ & iron limitation coefficient & 0.05 & - & tuned \\
\hline$d_{M L}$ & mixed layer depth & 20 & $m$ & W99 \\
\hline$v_{u w}$ & upwelling velocity & .1 & $m d^{-1}$ & A93 \\
\hline$w_{D}$ & D turnover rate due to sinking & 0.3750 & $d^{-1}$ & MD04 \\
\hline$g_{a}$ & $Z_{1}$ assimilation efficiency & 0.7 & - & DP02 \\
\hline$w_{A}$ & aggregation coefficient & 0.02 & $m m o l N^{-1} m^{3} d^{-1}$ & CV \\
\hline
\end{tabular}

Table 5. 
Figure 1. Model dynamics. State variables include nitrogen (N), small phytoplankton (P1), large phytoplankton (P2), small zooplankton (Z1), large zooplankton (Z2, prescribed), and detritus (D). Bold arrows denote export: detritus sinks (1), detritus and large phytoplankton form aggregates (2), and large phytoplankton and small zooplankton are consumed by large zooplankton (3). In steady state these losses are balanced by the input of $N$ via upwelling.

Figure 2. Maximum amplification of export flux following perturbations in all state variables that optimize export flux at time $\tau$. The perturbation that gives the maximum amplification is $\Phi_{F L U X}$ and corresponds to the perturbation that optimizes export flux at $\tau=9.3$ days.

Figure 3. Ecosystem response to perturbations $\Phi_{F L U X}(\mathrm{a}), \Phi_{F L U X-P}(\mathrm{~b}), \Phi_{I N T}(\mathrm{c})$, $\Phi_{P_{1} P_{2}}(\mathrm{~d})$, and $\Phi_{P_{1}}(\mathrm{e})$ for the first 150 days following the perturbation at $t=0$. The dashed lines show the steady state values for each state variable. In each panel, dark blue is $P_{1}$, green is $P_{2}$, red is $Z_{1}$, and teal is $D$.

Figure 4. Nitrogen response to perturbations $\Phi_{F L U X}(\mathrm{a}), \Phi_{F L U X-P}(\mathrm{~b}), \Phi_{I N T}(\mathrm{c})$, $\Phi_{P_{1} P_{2}}(\mathrm{~d})$, and $\Phi_{P_{1}}(\mathrm{e})$ for the first 150 days following the perturbation at $t=0$. Dashed lines show value at steady state.

Figure 5. Components of export flux anomaly (i.e. export flux anomaly at steady state is 0) in response to perturbations $\Phi_{F L U X}(\mathrm{a}), \Phi_{F L U X-P}(\mathrm{~b}), \Phi_{I N T}(\mathrm{c}), \Phi_{P_{1} P_{2}}$ (d), and $\Phi_{P_{1}}$ (e) for 150 days following the perturbation at $t=0$.. The solid black line is net export, the solid grey line is sinking detritus, the dashed grey line is aggregation, and the dashed black line is flux to higher trophic levels. 
Figure 6. Amplification (dimensionless, (21)) in response $\Phi_{F L U X}$ (solid black), $\Phi_{F L U X-P}$ (dashed black), $\Phi_{I N T}$ (solid grey), and $\Phi_{P_{1} P_{2}}$ (dashed grey). The time of the perturbations is $t=0$. Note that $\Phi_{P_{1}}$ is not included as amplification is infinite in response. 


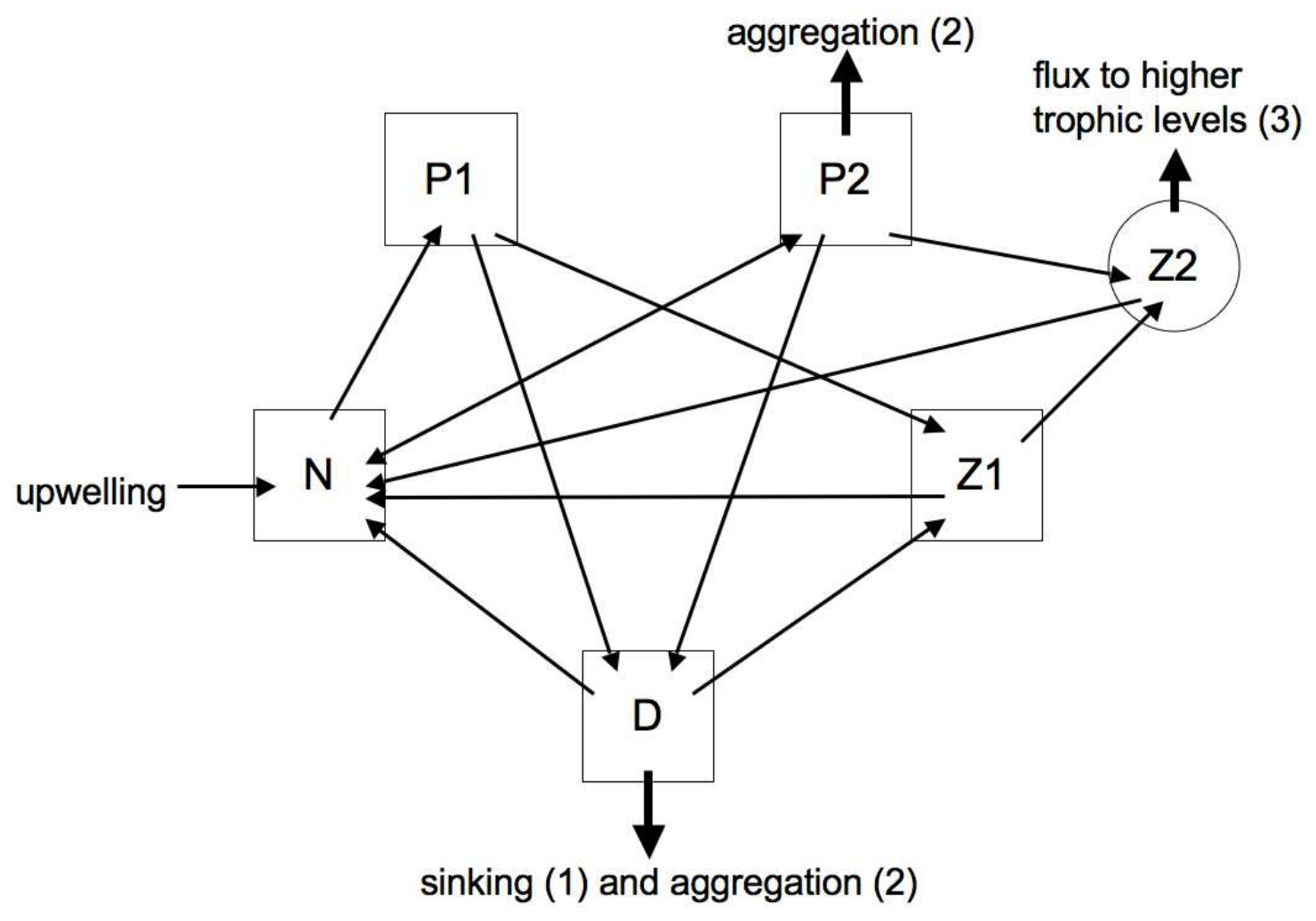

Figure 1. 


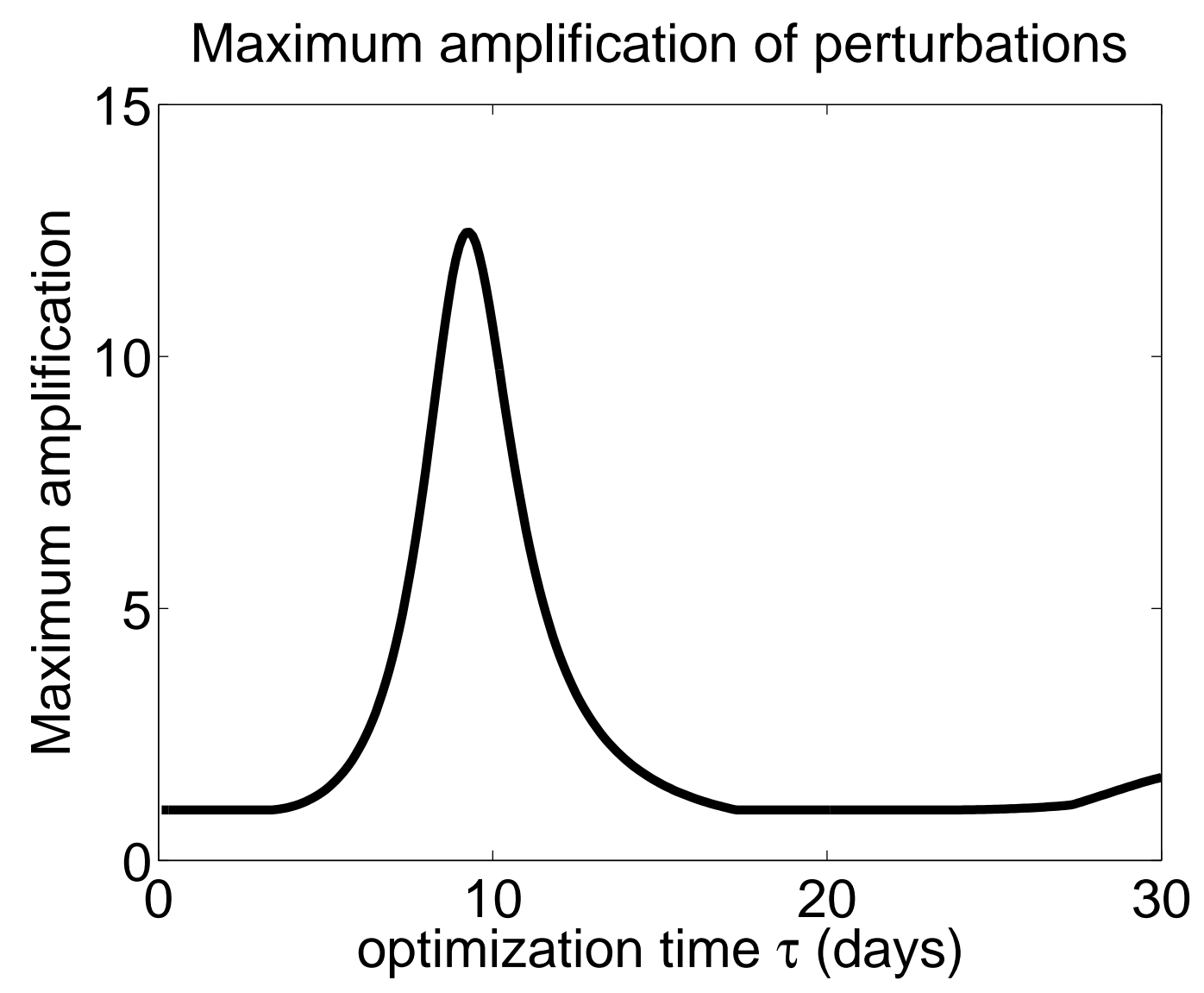

Figure 2. 
(a)

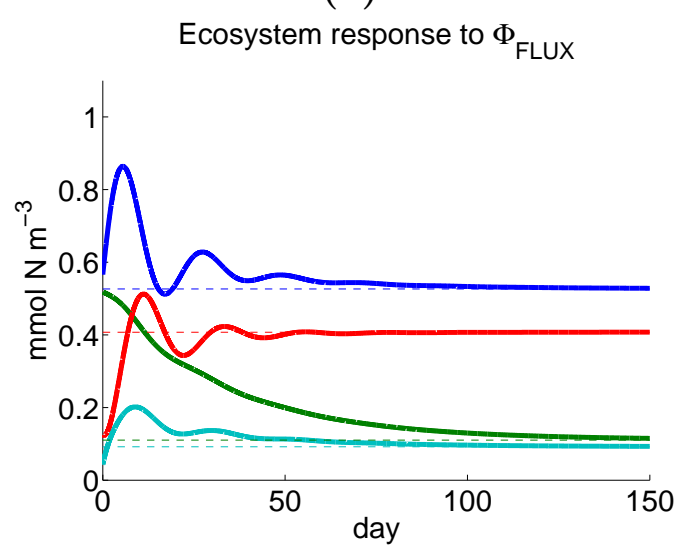

(c)

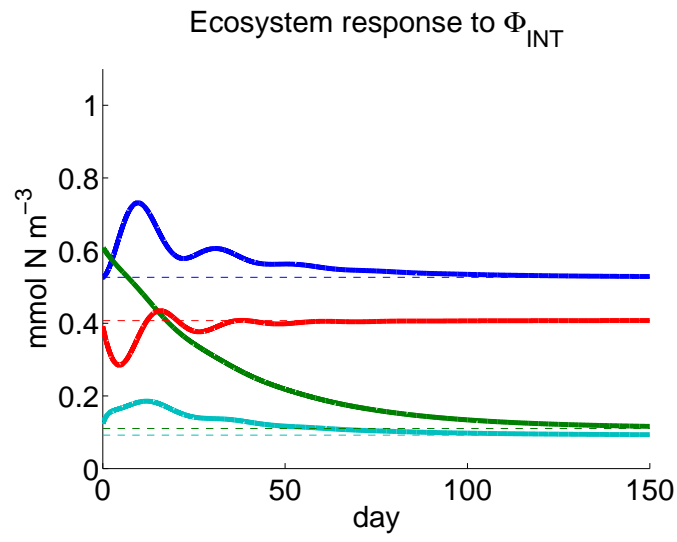

(e)

Ecosystem response to $\Phi_{\mathrm{P}_{1}}$

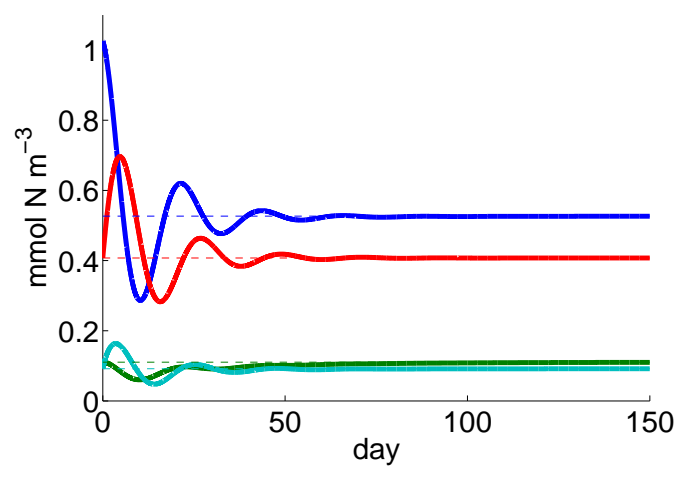

(b)

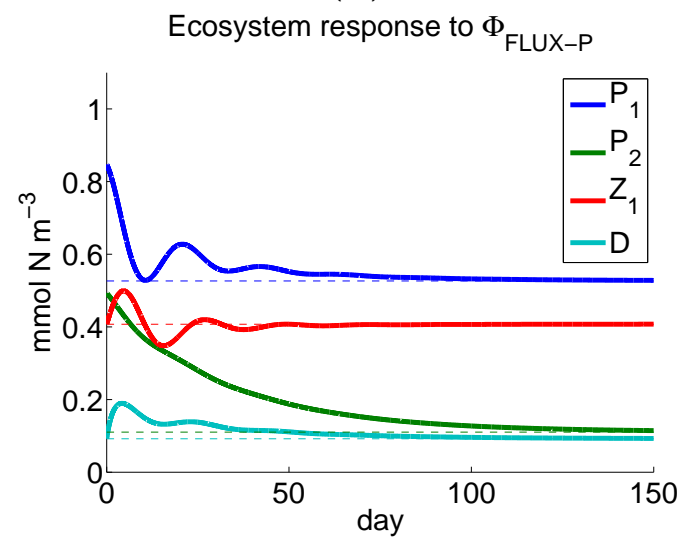

(d)

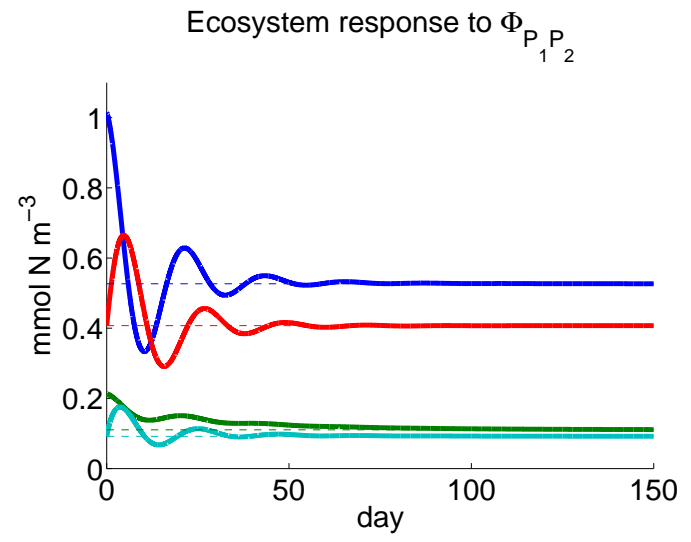

Figure 3. 
(a)

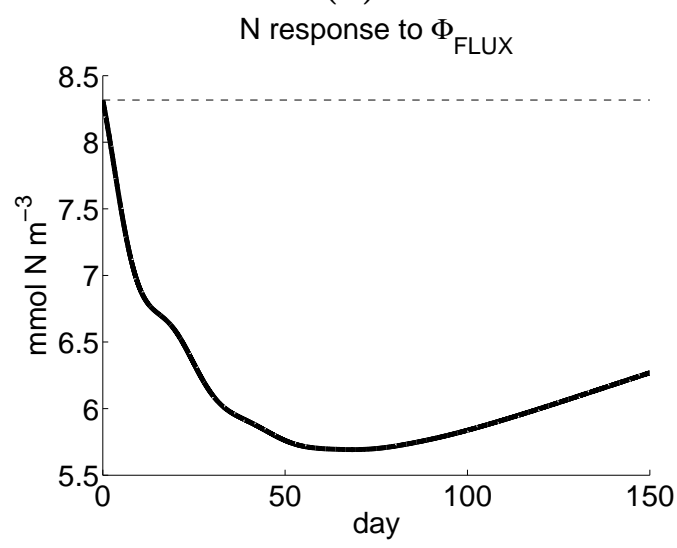

(c)

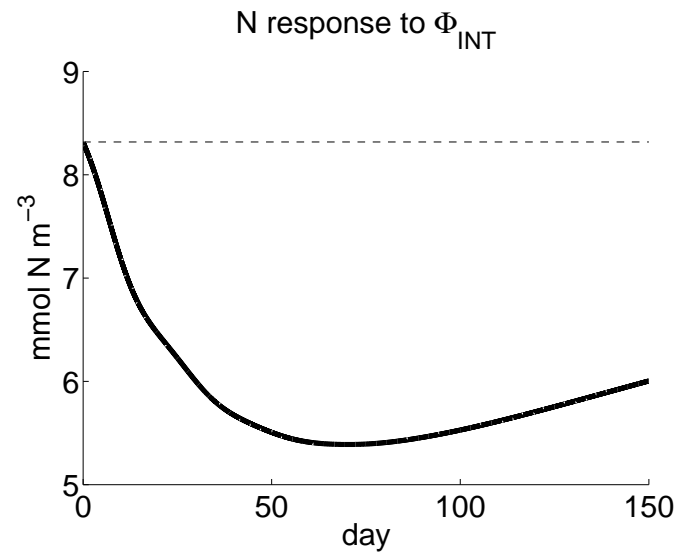

(e)

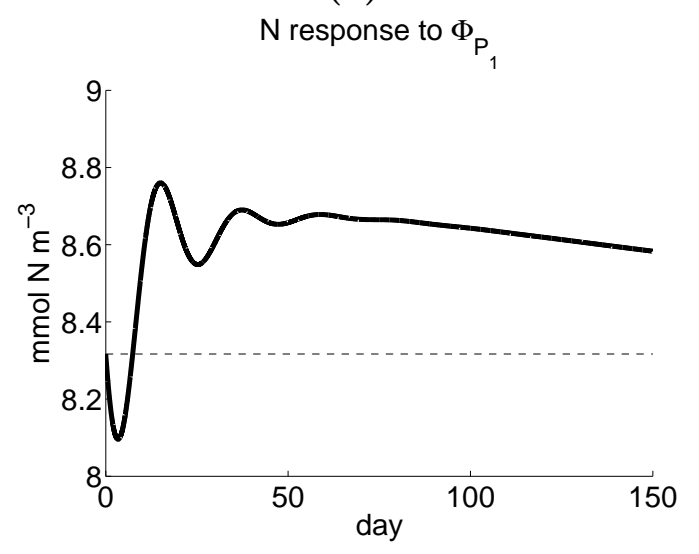

(b)

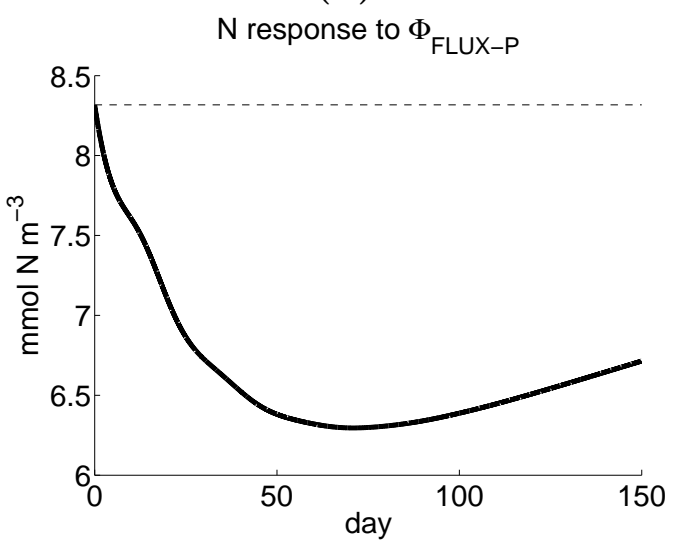

(d)

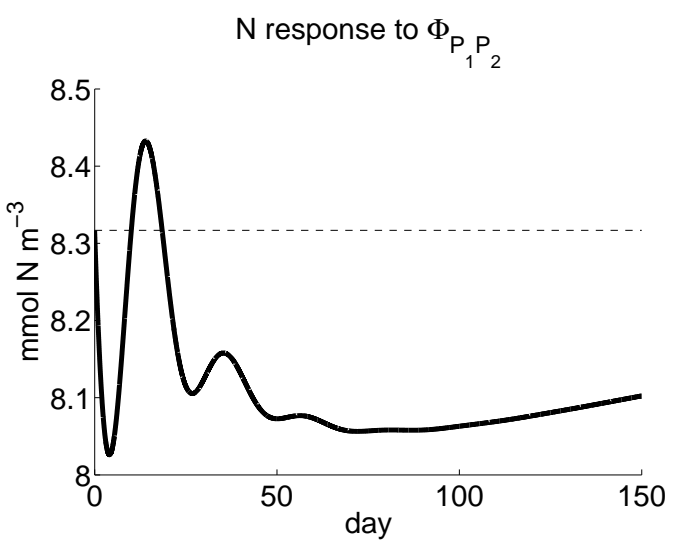

Figure 4 . 
(a)

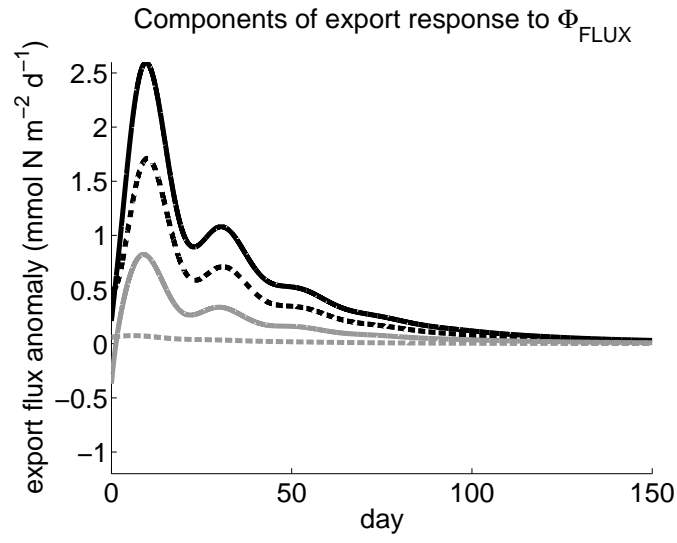

(c)

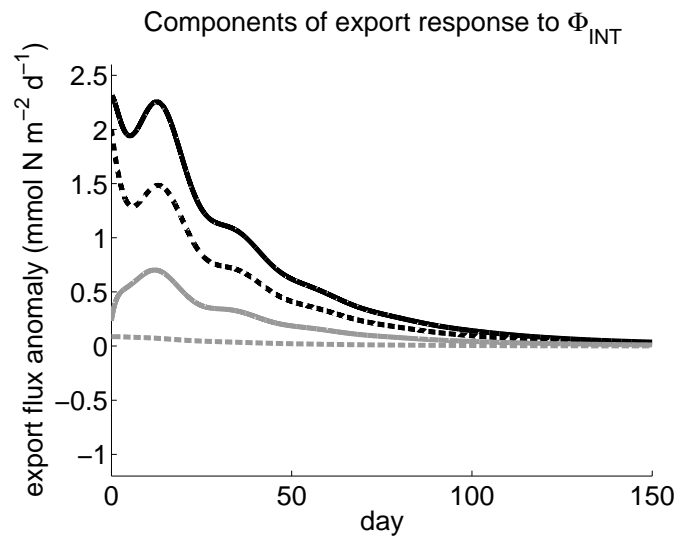

(e)

Components of export response to $\Phi_{\mathrm{P}_{1}}$

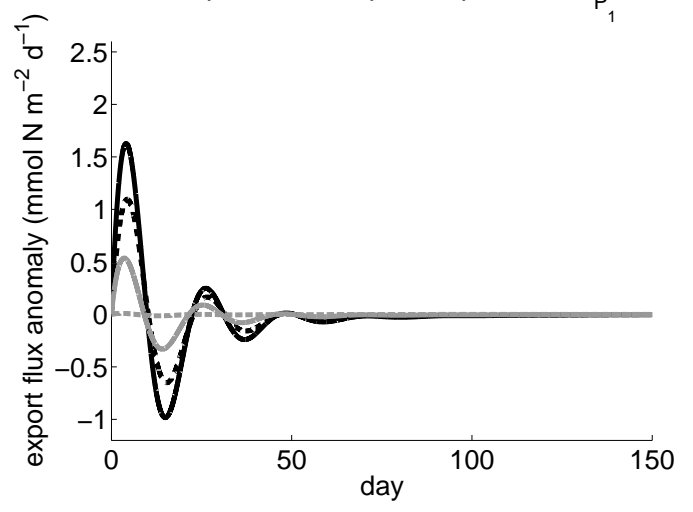

(b)

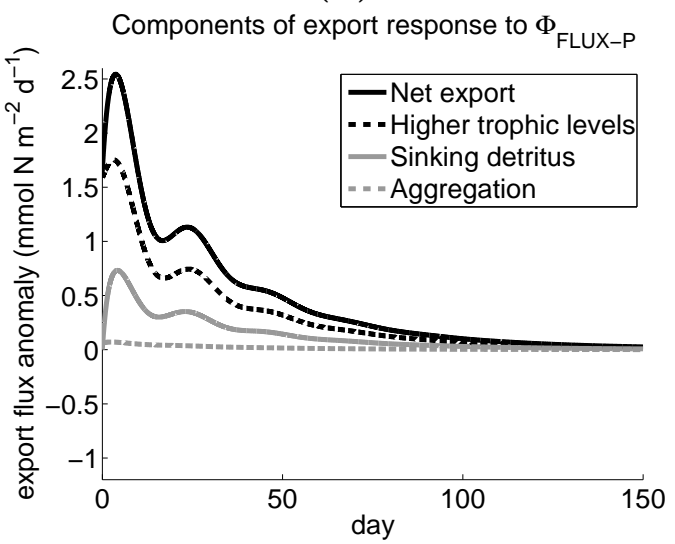

(d)

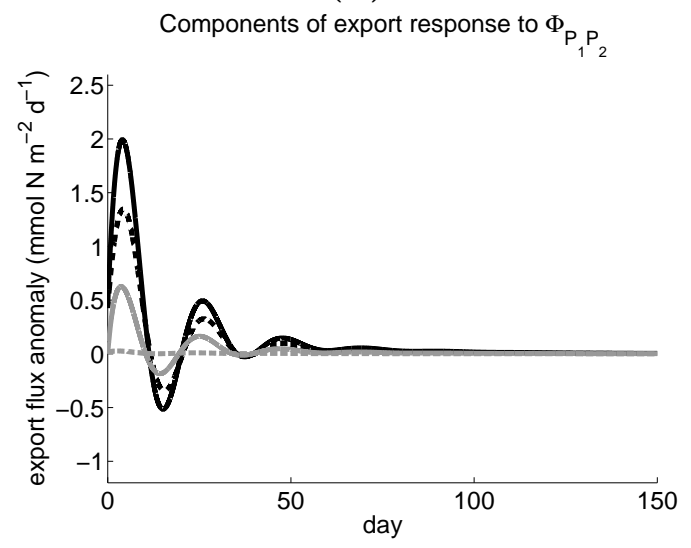

Figure 5. 


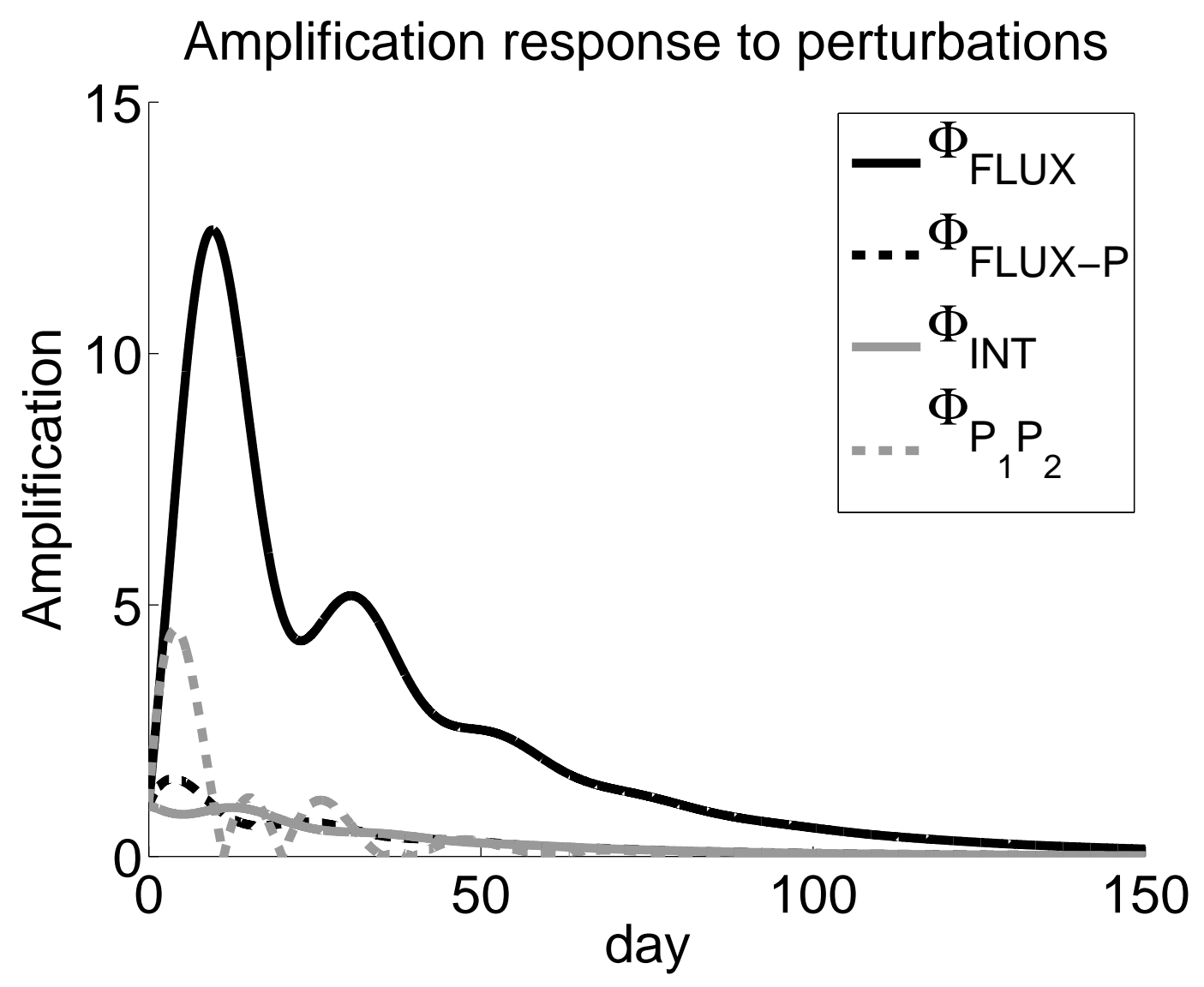

Figure 6. 